\title{
Knowledge Sharing in Workplace: Motivators and Demotivators
}

\author{
${ }^{1}$ Oye, N.D. ${ }^{2}$ Mazleena Salleh ${ }^{3}$ Noorminshah, A. \\ Faculty of Computer Science and Information System \\ Universiti Technologi Malaysia \\ 81310 Skudai, Johor
}

\begin{abstract}
This paper gives an overview of knowledge sharing in workplace. Based on the review of critical literatures by the authors, they infer that knowledge sharing in workplace can be influenced by motivators and demotivators. Activities of knowledge sharing in organizations may be on organization level or individual level. Knowledge sharing of both levels is critical to the success or failure of knowledge management inside and outside of organizations. Age, culture, and industry were all found to affect knowledge sharing among workers. A common stereotype is that older workers hoard knowledge because they are more insecure and feel threatened by younger workers. Since older workers have more valuable knowledge, younger workers needed to entice their older colleagues to share their valuable knowledge with them. The paper focus on motivators and demotivators to sharing Knowledge in workplace. Theories and research pertaining to why workers share knowledge are reviewed. While all industry need knowledge and innovation, it is also true that the pace of change and the need to innovate differs from industry to industry. Technology was acknowledged to have a high important role in increasing productivity of knowledge sharing. It plays a critical role in creating, storing and distributing explicit knowledge in an accessible and expeditious manner.
\end{abstract}

Keywords: - Knowledge, Sharing knowledge, Intrinsic and Extrinsic Motivators and Demotivators

\section{Introduciton}

Why are workers willing to share their knowledge with each other? The answer seems to vary depending on who is asked. Human resources departments believe that the incentive and performance management schemes they have put in place motivate their workers to share knowledge. In fact this is critical to the success or failure of knowledge management inside and outside of organizations [1]. Information technology (IT) departments point to the productivity tools and IT infrastructures they have put in place that collect, store, and distribute knowledge to anyone in the organization. Social psychologists have pointed out that workers form occupational communities or communities of practices (CoPs) within which knowledge sharing seems to occur naturally. The emergence of the knowledge-based economy, the vast size of global organizations, and the intensification of competition have come together to require organizations to be as agile and intelligent as they can be, and one important way for organizations to meet this requirement 
International Journal of Managing Information Technology (IJMIT) Vol.3, No.4, November 2011

is to enable organizational members to share their knowledge efficiently [2]. Knowledge sharing is therefore perceived as the key process in knowledge management. The most authoritative source as to why workers share knowledge must be the workers themselves, for they know better than anyone else why they are willing to share knowledge. First, knowledge is always tacit to begin with, that is, it exists only in workers' minds and cannot be articulated easily. The struggle is to articulate this knowledge and transfer it into a physical medium so that it can be distributed, reused and perhaps serve as the foundation of new knowledge [3]. Articulating knowledge requires workers to share their knowledge. The intention to share is derived from the motivation or willingness to share. A few researchers have highlighted instances where efforts to entice workers to share knowledge had failed but few have delved into why this occurred [4]. Knowledge workers will only share knowledge when there are compelling motivators to do so. Few studies have been done to ascertain what these motivators of knowledge sharing may be. The existing theories of motivation such as Expectancy Theory were formulated in the 1950s and 1960s for manufacturing workers in an industrial economy and, in practice if not in theory, assumed extrinsic benefits to be the prime motivators in modifying behavior and even corporate culture [5].

\section{Knowledge in Workplace}

This research predicts that the creation and dissemination of knowledge, especially in large organizations, requires both a cultural-social and a technological dimension. Firms must provide workers with IT infrastructures and ensure they use these infrastructures to create, store, and distribute their knowledge. The knowledge tools should be perceived as easy to use and as adding value to the workers' performance, or else the workers may be deterred from putting their knowledge into the systems. On the other hand, even if the knowledge systems are highly usable, usage alone is unproductive if the workers are not willing to share truly valuable knowledge with their colleagues and firms. Motivating employees to share knowledge is now seen more as a corporate culture rather than a technology issue. However, anecdotal and research findings suggest that national cultural differences can also impede information and knowledge flow within business organizations [6]. It is therefore important to identify and remove potential cultural both corporate and national - barriers to knowledge creation. Whether it is corporate or national culture, one of the main tools for modifying behaviors is the reward system [7]. In the past, the norm has been to reward outstanding individual performers who frequently have superior knowledge or skills not possessed by their peers because their contributions are seen as more critical to the firm or organization. Sharing their unique knowledge would be tantamount to jeopardizing their livelihood. Therefore, besides setting up effective IT infrastructures, firms must also create appropriate reward systems that will motivate workers to truly share knowledge - and do it using the IT systems provided.

\section{Literature Review on Knowledge}

Knowledge and its efficient management constitute the key to success and survival for organizations in the highly dynamic and competitive world of today. Efficient acquisition, storage, transfer, retrieval, application, and visualization of knowledge often distinguish successful organizations from the unsuccessful ones, and are essential for management of knowledge. Because "tacit knowledge held by individuals is the basis of organizational knowledge creation ... the sharing of tacit knowledge among multiple individuals with different 
International Journal of Managing Information Technology (IJMIT) Vol.3, No.4, November 2011

backgrounds, perspectives, and motivations becomes the critical step for organizational knowledge creation to take place. In this information age, knowledge remains a key element in business success, just as important as oil or coal during the industrial age [8][9] underlined the importance of knowledge for organizations by pointing out that the sum of knowledge acquired externally and internally constitutes a sustainable resource for maintaining competitive advantage. [10] also emphasized that organizational knowledge plays an important role not only in overall performance, but also in the competitiveness of an organization. Additionally, [11] and [12] works suggest that innovation is closely related to the concept of "knowledge creation". [13] define knowledge creation as: [. . .] a continuous process of learning by acquiring a new context, a new view of the world and new knowledge in overcoming the individual boundaries and constraints imposed by existing information parameters. To learn and acquire new knowledge, individuals should interact and share implicit and explicit knowledge with each other. In this way, individuals improve their capacity to define a situation or problem, and apply their knowledge for to problem solving [13]. Hence, knowledge sharing is a crucial issue in organizations [14]. Knowledge sharing is defined in accordance with [15] conceptualization; as a process where individuals mutually exchange their implicit (tacit) and explicit knowledge to create new knowledge. Most writers distinguish between explicit and tacit knowledge. [11] defines explicit knowledge as the knowledge, which has been codified and expressed in formal language. On the other hand, tacit knowledge is harder to express, represent and communicate, it is intuitive, unarticulated and cannot be verbalized [16]. Tacit knowledge is personal and hard to formalize. It is a less familiar, unconventional form of knowledge. As tacit knowledge is not codified, and not openly communicated, it is acquired by sharing experiences, and by observation and imitation [17][18][19]. Tacit and explicit knowledge are complementary, that is to say, they both are essential to knowledge creation. As such, knowledge is created via a spiral type of conversions between explicit and tacit knowledge. Sharing both kinds of knowledge is therefore vital for knowledge creation. According to [15] definition, knowledge sharing has two facets; collecting or receiving, and disseminating or donating, knowledge.

\section{Theories and Research Pertaining to Why Workers Share Knowledge}

These will be consider under the following points (i) The nature of knowledge, (ii) Knowledge creation: the SECI Model, (iii) knowledge creation: Ba, (iv) Motivation and (v) Motivation and Knowledge sharing.

\subsection{The nature of Knowledge}

One reason for the increasing interest in knowledge and its management is a differentiation between information and knowledge [20][21][22]. The leading view of business strategy today the resource-based theory of firms - believes sustainable competitive success can only come from strategic assets [23] and knowledge, not information. Information tells us of changes but does not make us capable of replicating those changes. To initiate changes, we must have something that makes us capable of evaluating data and information in the first place and then make decisions based on our evaluations. What gives us this capability is knowledge.[24] puts it succinctly when he said knowledge is "information that changes something or somebody - either by becoming grounds for actions, or by making an individual (or an institution) capable of different or more effective action. These differences based on Davenport's taxonomy are summarized and exemplified in Table 1 below[25]. 
International Journal of Managing Information Technology (IJMIT) Vol.3, No.4, November 2011

Table1: Data, Information, and Knowledge

\begin{tabular}{|l|l|l|}
\hline Data & Information & Knowledge \\
\hline Simple observations of & Data endowed with relevance & Value-added information from \\
states of the world & and purpose & The human mind including \\
Easily structured & Requires unit of analysis & Reflection, synthesis, context \\
Easily captured on machines & Need consensus on meaning & Hard to structure \\
Often quantifiable & Human mediation necessary & Difficult to capture on machine \\
Easily transferable & & Often tacit \\
& & Hard to transfer \\
\hline
\end{tabular}

\begin{tabular}{|l|l|l|}
\hline Example of data & Example of information & Example of knowledge \\
\hline Real-time stock price & Analysts' report of a stock- & $\begin{array}{l}\text { Fund managers' decision to buy } \\
\text { Temperature now is } 90^{\circ \mathrm{F}}\end{array}$ \\
& $\begin{array}{l}\text { Uptrend or downtrend } \\
\text { This is hot for Fall }\end{array}$ \\
& & $\begin{array}{l}\text { We need not wear a jacket } \\
\text { today }\end{array}$ \\
\hline
\end{tabular}

The financial markets provide a good example of the differences between data, information, and knowledge. For example, financial data such as real-time stock prices of companies are publicly available. This is legally required so as to ensure a level playing field for all participants in the financial markets because any party having access to additional data will have a significant advantage over the others. Financial managers have high-powered computer models to turn the data into information, such as whether a particular stock price is on an uptrend or downtrend. Because every manager is acting on the same information, we would expect every one of them to have a similar level of performance. However, in the real world, we find a few managers such as Berkshire Hathaway's Warren Buffet and Legg Mason's Bill Miller outperforming the industry average for long periods of time. (As of 2004, the Legg Mason Value Trust managed by Miller has outperformed the S\&P 500 index for 13 consecutive years. Under Warren Buffet's management, Berkshire Hathaway exceeded a $25 \%$ annual return to its shareholders for the last 25 years.) This superior performance can only be ascribed to the managers' knowledge - their unique experience, values, and insight which were brought to bear in interpreting the same information available to all their competitors.

\subsubsection{Explicit and tacit knowledge.}

From [26] simple observation that humans know more than they can tell, springs the idea that knowledge is made up of explicit knowledge and tacit knowledge. Explicit knowledge is defined as "intellectual material that has been formalized, captured and leveraged to produce a highervalued asset" [27]. It is tacit knowledge that has been codified and is therefore transmittable in formal systemic language. The distinctive feature of explicit knowledge and the reason why it is so valued is, it is easily stored, transported, distributed, and accessed in audio-visual (books, films, audio-tapes, and so forth) and digital (databases, knowledge repositories, intranets, and so forth) forms. Tacit knowledge is personal and context-specific, that is, based on personal experience over a long period of time. The term tacit knowledge is conventionally opposed to explicit knowledge, and is used to describe knowledge which cannot be explicitly represented. [28], opine that tacit knowledge has received attention as a predictor of future success. However, despite the increasing interest in tacit knowledge, measuring and sharing it remains problematic. 
International Journal of Managing Information Technology (IJMIT) Vol.3, No.4, November 2011

\subsection{Knowledge Creation: The SECI Model}

\subsubsection{Socialization.}

New knowledge begins as tacit knowledge as "Knowledge is created only by individuals. An organization cannot create knowledge without individuals" [12]. Individuals acquire tacit knowledge "through shared experience, such as spending time together or living in the same environment ..." by empathizing with customers, suppliers, and even competitors in day-to-day interaction [29]. This can be as simple as walking around the shop floor perceiving what is going on or as formalized as an apprenticeship.

\subsubsection{Externalization.}

After acquiring tacit knowledge, individuals "try to rationalize and articulate the world that surrounds them.... Tacit knowledge is made explicit so that it can be shared by others to become the basis of new knowledge such as concepts, images, and written documents"[29]. This process of articulation requires individuals to share their knowledge with others through dialogue and self-reflection. IT may also directly affect the workers' motivation to articulate their tacit knowledge in the externalization process.

\subsubsection{Combination.}

In this mode, the articulated knowledge is collected, processed, reconfigured, and disseminated among members of the organization as new explicit knowledge. Combining the articulated tactic knowledge, concepts and documentations are created and then distributed. In the combination process, "justification of knowledge takes place so as to form the basis for agreement...[30], that is, explicit knowledge is circulated throughout the organization so that members of the organization can consider and form a consensus on which pieces of explicit knowledge or combinations thereof are truly worthwhile[31][32].

\subsubsection{Internalization.}

The newly created explicit knowledge "is applied and used in practical situations ...through action, practice, and reflection so that it becomes knowledge of one's own" [29]. In the process, the explicit knowledge is converted into new tacit knowledge by the individuals using it. In so doing, individuals acquire new tacit knowledge which can be used as feed stock in a new socialization process for another round of knowledge creation. As in the externalization and combination modes, workers are likely to be receiving the explicit knowledge via IT systems and these systems may affect their motivation in the internalization process. Below is a figure showing the four modes of the SECI model and the process of converting tacit knowledge into explicit knowledge 


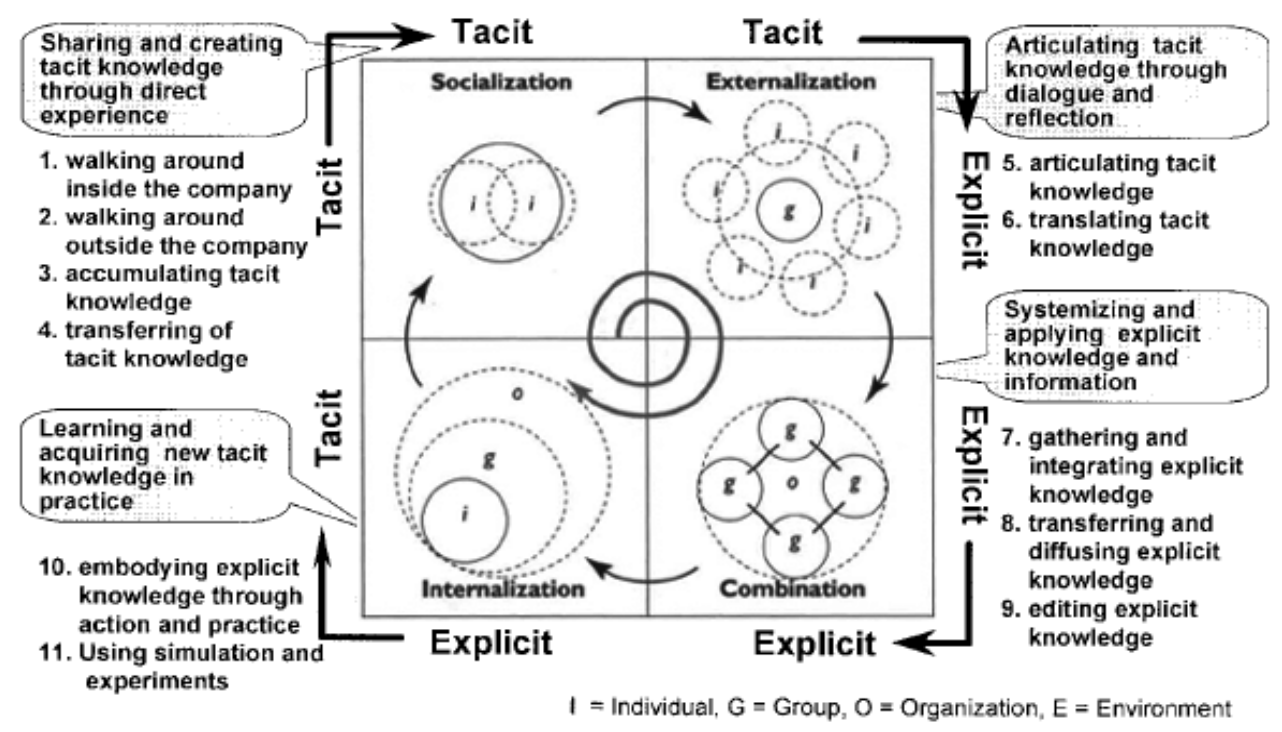

Figure 1: SECI model of knowledge creation (reproduced from [29] )

The SECI Model explained how knowledge is created but did not address the questions of the context or the basic conditions required for this process to take place.

\subsection{Knowledge Creation: Ba}

In 1998, Nonaka and Konno advanced a generic existentialist concept they called Ba to address some of these questions. Ba is the "shared space for emerging relationships" and for the "resource concentration" of the organization's knowledge assets and capabilities underlying all knowledge creation. "Ba offers the interpretative flexibility required for the effective appropriation of new methods and generates the team working and cooperation among the staff necessary to introduce innovative systems" [33].

\subsection{Motivation}

Among the questions yet to be answered is what potentialities and tendencies in a knowledgecreating $\mathrm{Ba}$ hinder or motivate individual workers to share knowledge. [34],[35] said "Because tacit knowledge is highly personal to the individual or team, its value to the firm will depend greatly on the individual's willingness to apply it to serve the interests of the firm, or to assist in its conversion to codified form, which enables it to be used by colleagues. Knowing that, the individual will recognize the power that gives him or her and will be aware that it is a form of personal property right that will not be given away lightly. Theories that emphasize extrinsic motivation were based on the scientific management approach and view workers as making logical economic calculations. The fundamental assumption is that workers can be motivated with an economic threat/reward system and would increase their output according to incremental financial incentives. Work behavior is therefore logical, predictable, and manageable. Theories that emphasize intrinsic motivation, on the other hand, view workers as social beings striving to fulfill innate human needs. This stemmed from the famous Hawthorne studies in the 1930s where 
International Journal of Managing Information Technology (IJMIT) Vol.3, No.4, November 2011

counter-intuitively, productivity was demonstrated to improve with reduced work hours and amelioration to boredom and monotony on the job. As a result, the focus of motivation research changed to the satisfaction of human needs which crystallized in the needs theories of the 1950s.

\subsubsection{Needs theories: Hierarchy of needs.}

Maslow's hierarchy of needs [52] hypothesizes that human behavior is motivated by five types of needs:

- Basic/physiological (food, water, and so forth)

- Safety

- Belonging/love (affection, friendship, and so forth)

- Esteem (self-respect, recognition from peers, and so forth)

- Self-actualization (realizing one's potential - order, simplicity, richness, and so forth)

Maslow postulates that each type of needs must be satisfied in turn before the next, starting with the basic needs required for survival. The first four types - collectively called deficiency needs (D-needs) - stop being motivators after they have been met. However, after meeting their deficiency needs, people can finally move to fulfill the last need - self-actualization, also called growth needs (B-needs) such as the desire for beauty, truth, and justice. Unlike deficiency needs, growth needs are perpetual motivators. While Maslow has been criticized for not explaining how behavior is affected within the hierarchy and a lack of empirical evidence, the three highest needs still seem relevant for motivating knowledge workers [36].

\subsubsection{Needs theories: Motivation-Hygiene Theory.}

[37] proposed the Motivation-Hygiene Theory (also called the Two Factor Theory) in 1959 when he hypothesized that human behavior is influenced by two types of factors. Herzberg proposed that "factors involved in producing job satisfaction (and motivation) are separate and distinct from the factors that lead to job dissatisfaction [because] .... The opposite of job satisfaction is not job dissatisfaction but, rather, no job satisfaction; and similarly, the opposite of job dissatisfaction is not job satisfaction, but no job dissatisfaction"[37]. Satisfaction and motivation are caused by the existence of motivation factors while dissatisfaction and demotivation are a result of insufficient hygiene factors. As he explained above, a surplus of hygiene factors such as salary, status, and quality of supervision will not result in greater motivation although a deficit of them will result in demotivation. To create motivation, motivation factors such as recognition for achievement, an interesting job, and advancement must exist. Herzberg (and Maslow) has been criticized for not accounting for individual differences, that is, not everyone is motivated to the same degree or even by the same factors. However, Herzberg's theory is relevant "when studying the factors influencing the motivation for knowledge sharing... People share knowledge because they expect or hope for recognition and appreciation of their (knowledge) work, promotional opportunities or because of a sense of responsibility. Even the same individual was motivated by different factors at different stages of his life. [38] related an interesting example of why an incentive bonus scheme in a British factory had mixed results. He found that workers who were recent school-leavers still stayed with their families. They were expected to hand over their pay to their mothers who gave them back a small amount of spending money. When the workers got older, the situation was reversed and they kept their pay and gave their mothers a small amount 
International Journal of Managing Information Technology (IJMIT) Vol.3, No.4, November 2011

for their lodging at home. As a result, the younger workers were not motivated by the bonus but became highly motivated as they got older.

\subsubsection{Expectancy theory.}

In the 1970s, there was a move back to extrinsic motivation albeit tailored to individual desires. [39] Expectancy Theory (ET) became accepted for explaining the process of motivation in the workplace. The underlying assumption of ET is that workers make conscious and rational choices about the effort they put into their jobs in order to get the rewards (such as higher pay or praise) they want or to avoid punishment. For example, because most workers have the goal of maximizing their incomes, the firm can use this goal to make them increase their productivity (make more sales, for example) by offering them bonuses if they meet a certain sales quota. This would motivate each worker to do his personal best and ensure the firm gets the most out of each worker.

\subsection{Motivation and Knowledge Sharing}

"Knowledge does not move without motivating force, and people will not give away valuable possessions such as knowledge without concern for what they may gain or lose in the process" [40];[41].

\subsubsection{Different inputs.}

The main input of a knowledge economy is the knowledge workers. [43] believes knowledge workers today have different sociological and psychological drivers compared to workers of previous generations. [42] reports that knowledge workers are paid over $30 \%$ more than other types of workers, not including excellent fringe benefits and stock options, even during the technology recession. These workers are also much better educated with scientific and technical knowledge than the previous generations -The organization needs the workers more than the workers need the organization. Hence, instead of extrinsic motivation, knowledge workers are instead seeking intrinsic motivation in social recognition and power [51].[43], noting it is common for knowledge workers to trade material rewards for sociological ones, Amar is, in effect, suggesting using extrinsic rewards to create intrinsic motivation believing intrinsic motivation will be much more effective and permanent.

\subsubsection{Different cultures.}

In the globalized economy, a corporation's employees are drawn from many nationalities all over the world. Workers from different national cultures may be motivated by different motivators or at least by different quantities of the same motivator. The requirements for a conducive Ba may well be different for different national cultures. The most commonly used definition of national culture is the collective programming of the mind that makes one group of people share a tendency towards certain values and preference towards certain states of affairs from another group [44]. Based on a survey of 117,000 IBM employees in 71 countries from 1967-1973, Hofstede identified five universal dimensions that could be used to compare national cultural tendencies. These are power distance, individualism/collectivism, uncertainty avoidance, masculinity/femininity, and long-term orientation. Different nations rated differently on these five dimensions. For example, Japan's culture was high in power distance, low in individualism, and 
International Journal of Managing Information Technology (IJMIT) Vol.3, No.4, November 2011

very high in uncertainty avoidance. This indicated Japan may have more hierarchical organization structures, value collective accomplishments more, and be more rule-oriented (laws, rules, regulations and controls) in order to reduce the amount of uncertainty. These differences may also affect knowledge sharing or transfer. [45] argue that cultures high on collectivism may find it easier to share knowledge and cultures high on power distance may have a more top-down flow of knowledge. [45] found language was the biggest cultural barrier between the Japanese expatriate workers and American workers there. A lot of knowledge was lost in translation or due to the inability to articulate the knowledge in the second language. The Japanese workers tend to have a more top-down knowledge flow while the Americans' knowledge flow tends to be more diverse (top-down, lateral, and bottom-up). To their surprise, they did not find other significant cultural differences between the Japanese and the Americans and they attribute this to the Westernization of Japanese youth.

\subsubsection{Different context.}

These well-rewarded, multicultural, multinational knowledge workers also live under a new precarious psychological contract. Social psychologists advance the concept of a 'psychological contract' to describe the strong emotional ties and loyalties that develop between employees and their jobs. As a result, "the psychological contract existing under the lifetime employment model has been replaced with a strong element of precariousness in the employment relationship... [which adversely] impacts the level of trust that they place in their organizations, management and fellow workers, and their willingness to share their knowledge for use by the organization" [46]. Trust is defined as "a psychological state comprising the intention to accept vulnerability based upon positive expectations of the intentions or behavior of another" [47]. Dirks and Ferrin reviewed 43 studies and found strong support that trust is a necessary although not sufficient condition for cooperative and risky activities like knowledge sharing.[48] and[49] concurred that no matter how motivated they are, people do not share knowledge with those they do not trust. [50] found that the level of trust affects not only the sharers but the seekers of knowledge too.

On the other hand, with trust, even people with weak ties are able to share knowledge effectively. Sharkie conceptualizes a model of six perceptive factors that affect the level of trust workers have in their organization and their resultant predisposition or otherwise to share their knowledge with their organization. The factors are:

(i). the worker's employment security with the organization, (ii) the employer's improving an individual's employability, (iii). enlightened management, (iv). perception of fairness,(v). supportive environment, and

(vi). rewards for work done.

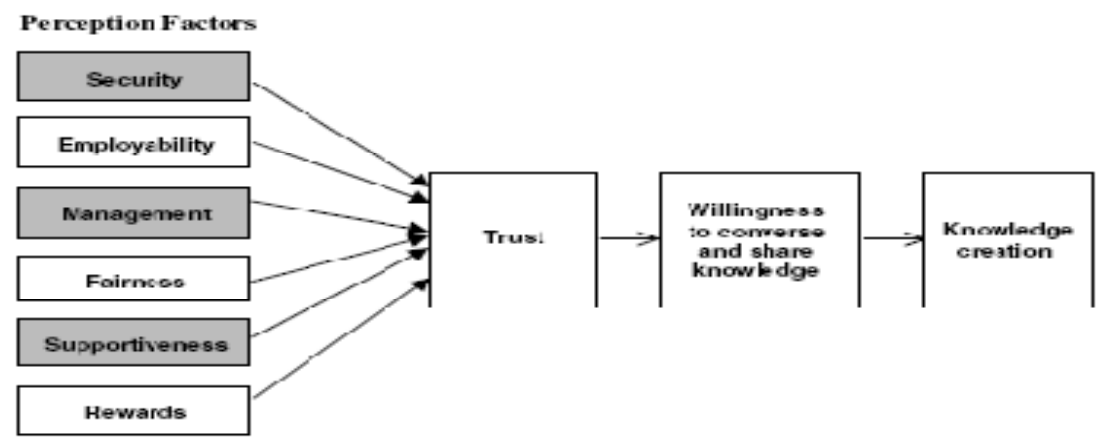

Figure 2: Model of Trust and Willingness to Share Knowledge (Reproduced From [46]) 
International Journal of Managing Information Technology (IJMIT) Vol.3, No.4, November 2011

In view of the precariousness of employment in the modern workplace, the lack of trust may be a significant barrier to creating the kind of Ba required for knowledge creation.

\section{The technology-infused workplace.}

[55] opined that ICT allows for effective transfer of knowledge anywhere and anytime regardless of subject matter.

The use of technology can certainly be seen as a maintenance factor to knowledge sharing, that is, it is a necessary but not sufficient condition for knowledge sharing. In other words, the ability or willingness to use technology in the knowledge sharing process will not motivate workers to share knowledge but the inability or unwillingness to use technology will demotivate workers from sharing knowledge. Not only do workers feel great ownership over the knowledge they create, but they understand that sharing knowledge is risky. The creator of the tacit knowledge has no personal need to share it because he already possesses and uses it for himself. If he shares his tacit knowledge, it is solely for the benefits of others. There is a cost of time and effort required to articulate that knowledge which is often not recognized by the worker's employer as part of his job. An even greater cost is the vulnerability associated with revealing one's thought process and knowledge to attack, misuse, or opportunism from other workers, hence the importance of a Ba rich with trust. The inputs, context, and outputs of knowledge work today are quite different from those of the traditional workplace that the established theories of motivation were initially formulated to explain. The knowledge workplace is more diverse culturally, much better educated and rewarded, but more precarious psychologically. As a result, trust and loyalty are rare qualities in the knowledge workplace.

\section{Why do Workers not Share Genuine Knowledge with their Colleagues?}

Workers do not share genuine knowledge with their colleague because of the following reasons: Protecting one's competitive edge, Job insecurity, Personal animosity, and Personal traits, shared knowledge not accepted or comprehended, Harm themselves or others with the knowledge, Confidentiality, and Lack of a sharing culture. Given the evidence above, we conclude that knowledge workers possess a great deal of valuable knowledge - explicit as well as tacit. However, knowledge sharing is the basis of knowledge work and therefore, ironically, knowledge workers are constantly required to devalue themselves by sharing valuable knowledge. To remain viable in the knowledge workplace, knowledge workers have to constantly replenish their stock of valuable knowledge. Therefore knowledge will only be shared with those who could offer other valuable knowledge in turn. The knowledge economy is basically a knowledge market where its workers trade knowledge or its proxies constantly. Therefore, ironically, in an industry that depends on knowledge sharing, knowledge can and will not be shared freely. The motivators and demotivators of sharing knowledge are listed in Table 8. 
International Journal of Managing Information Technology (IJMIT) Vol.3, No.4, November 2011

Table 8. Motivators and Demotivators to Share Knowledge

\begin{tabular}{|l|l|l|}
\hline Intrinsic & $\begin{array}{l}\text { Motivators } \\
\text { Job security } \\
\text { Professionalism } \\
\text { Social ties }\end{array}$ & $\begin{array}{l}\text { Pemotivators } \\
\text { Job security } \\
\text { Personal ties } \\
\text { Personal animosity }\end{array}$ \\
\hline Extrinsic & $\begin{array}{l}\text { Mutual benefit } \\
\text { Performance } \\
\text { review }\end{array}$ & $\begin{array}{l}\text { Shared knowledge } \\
\text { not } \\
\text { accepted/comprehen } \\
\text { ded } \\
\text { Harm themselves or } \\
\text { others } \\
\text { Confidential } \\
\text { Lack of sharing } \\
\text { culture } \\
\text { Making } \\
\text { discover knowledge } \\
\text { by themselves }\end{array}$ \\
\hline
\end{tabular}

Many of these motivators and demotivators are interrelated. The pervasive job insecurity accentuated some personal animosity and the instinct to protect one's edge. The intrinsic desire to defend against this threatening environment created knowledge fortresses which were sometimes cloaked as the extrinsic need to preserve confidentiality or to prevent others from harming themselves. The extrinsic lack of a sharing culture or management leadership accentuated the intrinsic job insecurity and personal animosity or lack of trust among the workers. These interrelationships are true for organizations, as well, which often hide knowledge from within and without to prevent their competitors from understanding their competitive edges and to maintain their images in the eyes of their customers. The main counterbalances to the demotivating climate were the professionalism of the workers and their social ties to each other. Extrinsic factors play a relatively minor role in motivating workers to share knowledge.

Professionalism and social ties were the other two types of intrinsic motivation identified. Social ties seemed to be the key to knowledge sharing in CoPs because workers in the same CoP who had not developed strong social ties would only share minimally or not at all. The strongest reason for not sharing knowledge was the lack of job security. In an insecure environment, trading knowledge with each other was a strategy used by knowledge workers to enhance their skills and their employability. In this instance, knowledge was not shared as a public good but as a commodity traded in a social exchange.

\section{Conclusions}

Therefore, while all industries need knowledge and innovation, it is also true that the pace of change and the need to innovate differs from industry to industry. Technology was acknowledged to have a highly important role in increasing the productivity of knowledge sharing. It plays a critical role in creating, storing, and distributing explicit knowledge in an accessible and 
International Journal of Managing Information Technology (IJMIT) Vol.3, No.4, November 2011

expeditious manner. Knowledge sharing is an important part of knowledge management and its success or failure will be directly related to how much knowledge could be used by more people. To understand the development of competitive advantage, we must understand knowledge and how it is shared. However, because of the complex nature of knowledge defining, knowledge is undisputedly a big challenge. Based on review of critical literatures, by the authors, knowledge sharing in workplace is determined by motivators and demotivators. Many factors have been identified as facilitating knowledge sharing in an organization, and culture is often considered as one of the critical ones. Again knowledge in itself and anticipated mutual relationship, hinges on interpersonal knowledge exchange [53][54]. Therefore work experience has a stronger effect on knowledge sharing in workplace. Undoubtedly, knowledge acquisition positively affects attitude towards knowledge sharing.

\section{Acknowledgment}

The authors would like to thank Prof. Nonaka, I. for allowing the use of SECI Model of Knowledge Creation for this review paper. In addition the authors gratefully acknowledge UTM, Research Universiti Malaysia for their support and encouragement.

\section{Reference}

[1] Ni C. ,Knowlegde Sharing and Knowledge Broker of Organizations: Second International Conference on Future Information Technology and Management Engineering. 978-07695-3880-8/09. 2009 IEEE.

[2] Nissen, M.E., "Knowledge management and global cultures: elucidation through an institutional knowledge-flow perspective', Knowledge and Process Management, 2007. Vol. 14 No. 3, pp. 21125.

[3] Pfeffer, J., \& Sutton, R. I. Knowing "what "to do is not enough: Turning knowledge into action. California Management Review, 1999. 42(1), 83-108.

[4] Pfeffer, J., \& Sutton, R. I,Knowing "what "to do is not enough: Turning knowledge into action. California Management Review, 1999. 42(1), 83-108.

[5] Kerr, J., \& Slocum, J. W., Managing corporate culture through reward systems. Academy of Management Executive, 1987. 1(2), 99-108.

[6] Matheson, L. R., \& Tarjan, R. E. ,Culturally induced information impactedness: A prescription for failure in software ventures. Journal of Management InformationSystems, 1998. 15(2), 23-40.

[7] Recardo, R., \& Jolly, J., Organizational culture and teams. S.A.M. Advanced Management Journal, 1997. 62(2), 4-8.

[8] Zhang, D.J. and Zhao, L. ,Knowledge management in organizations”, Journal of Database Management, 2006. Vol. 17 No. 1, pp. 1-9.

[9] Voelpel, S.C., Eckhoff, R.A. and Fo“rster, J.,"David against Goliath? Group size and bystander effects in virtual knowledge sharing”, Human Relations, 2005.Vol. 61 No. 2, pp. 271-95.

[10] Nilakanta, S., Miller, L.L. and Zhu, D.,"Organizational memory management: technological and research issues", Journal of Database Management, 2006. Vol. 17 No. 1, pp. 85-95.

[11] Nonaka, I.,"The knowledge-creating company", Harvard Business Review, 1991.Vol. 69 No. 6, pp. 96-104.

[12] Nonaka, I., \& Takeuchi, H. ,A dynamic theory of organizational knowledge creation. Organization Science, 1994. 5(1), 14-37.

[13] Nonaka, I., Von Krogh, G. and Voelpel, S.,"Organizational knowledge creation theory: evolutionary paths and future advances”, Organization Studies, 2006. Vol. 27 No. 8, pp. 1179-208.

[14] Sa'enz, J., Aramburu, N. and Rivera, O.,"Knowledge sharing and innovation performance; a comparison between high-tech and low-tech companies", Journal of Intellectual Capital, 2009.Vol. 10 No. 1, pp. 22-36. 
International Journal of Managing Information Technology (IJMIT) Vol.3, No.4, November 2011

[15] Van Den Hooff, B. and De Ridder, J.A.,"Knowledge sharing in context: the influence of organizational commitment, communication climate and CMC usage on knowledge sharing", Journal of Knowledge Management, 2004. Vol. 8 No. 6, pp. 117-30.

[16] Li, M. and Gao, F., "Why Nonaka highlights tacit knowledge: a critical review", Journal of Knowledge Management, 2003. Vol. 7 No. 4, pp. 6-14.

[17] Seidler-de Alwis, R. and Hartmann, E.,"The use of tacit knowledge within innovative companies: knowledge management in innovative enterprises", Journal of Knowledge Management, 2008. Vol. 12 No. 1, pp. 133-47.

[18] Kikoski, C.K. and Kikoski, J.F., The Inquiring Organization: Tacit Knowledge, Conversation, and Knowledge Creation Skills for 21st-Century Organizations, Praeger, Westport, CT. 2004.

[19] Hall, H., Input-friendliness: Motivating knowledge sharing across intranets. Journal of Information Science, 2001. 27(3), 139-146.

[20] Holsapple, C. W., \& Joshi, K. D. ,Knowledge management: A threefold framework. The Information Society, 2002. 18(1), 47-64.

[21] King, W. R., Playing an integral role in knowledge management. Information Systems Management, 2000.17(4), 59-61.

[22] Kreiner, K. ,Tacit knowledge management: The role of artifacts. Journal ofKnowledge Management 2002., 6(2), 112-123.

[23] Meso, P., \& Smith, R. ,A resource-based view of organizational knowledge management systems. Journal of Knowledge Management, 2000. 4(3), 224-234.

[24] Drucker, P. ,Post-capitalist society. 1993. Oxford: Butterworth Heinemann.

[25] Davenport, T. H. ,Information ecology: Mastering the information and knowledge environment. New York, NY: Oxford University Press. 1997.

[26] Polanyi, M, The tacit dimension. Garden City, N.Y: Anchor Books. 1966.

[27] Stewart, T. A. ,Intellectual capital: The new wealth of organizations. New York, NY: Doubleday. 1997.

[28] Lifeng,Yang. Knowlegde , Tacit Knowledge and Tacit Knowledge Sharing. 978-1-4244-4639-1/09, 2009. IEEE.

[29] Nonaka, I., \& Toyama, R., The knowledge-creating theory revisited: Knowledge creation as a synthesizing process. Knowledge Management Research \& Practice,2003. 1(1), 2-10.

[30] Nonaka, I., Konno, N., \& Toyama, R. ,Emergence of "Ba". In I. Nonaka \& T. Nishiguchi (Eds.), Knowledge Emergence: Social, Technical, and Evolutionary Dimensions of Knowledge Creation. New York, NY: Oxford University Press. 2001.

[31] Nonaka, I., \& Konno, N. ,The concept of "Ba": Building a foundation for knowledge creation. California Management Review, 1998. 40(3), 40-54.

[32] Nonaka, I., \& Toyama, R. ,The theory of the knowledge-creating firm: Subjectivity, objectivity and synthesis. Industrial and Corporate Change, 2005. 14(3), 419-436.

[33] Bennett, R,"Ba" as a determinant of salesforce effectiveness: An empirical assessment of the applicability of the Nonaka-Takeuchi model to the management of the selling function. Marketing Intelligence \& Planning, 2001. 19(3), 188-199.

[35] Hunter, L., Beaumont, P., \& Lee, M. ,Knowledge management practice in Scottish law firms. Human Resource Management Journal, 2002. 12(2), 4-21.

[36] Tampoe, M. ,Motivating knowledge workers - the challenge for the 1990s. In P. S. Myers (Ed.), Knowledge management and organization design. Boston, MA: Butterworth-Heinemann. 1996.

[37] Herzberg, F. ,One more time: How do you motivate employees. Harvard Business Review 2003., 81(1), 86-96.

[38] Millward, N. ,Family status and behaviour at work. Sociological Review, 1968. 16(2).

[39] Vroom, V. H. ,Work and motivation. New York, NY: Wiley. 1964.

[40] Davenport, T. H., \& Prusak, L. ,Working knowledge: How organizations manage what they know. Boston, MA: Harvard Business School Press. 1998.

[41] Stenmark, D. ,Turning tacit knowledge tangible. Paper presented at the 33rd Hawaiian International Conference on System Sciences, Maui, Hawaii. 2000.

[42] Drolet, M., \& Morissette, R. ,Better jobs in the new economy? Perspectives, 2002. 24-34. 
International Journal of Managing Information Technology (IJMIT) Vol.3, No.4, November 2011

[43] Amar, A. D,Motivating knowledge workers to innovate: A model integrating motivation dynamics and antecedents. European Journal of Innovation Management, 2004 .7(2), 89-101.

[44] Hofstede, G., \& McCrae, R. R. ,Personality and culture revisited: Linking traits and dimensions of culture. Cross-Cultural Research, 2004. 38(1), 52-88.

[45] Ford, D., \& Chan, Y. ,Knowledge sharing in a cross-cultural setting: A case study (pp. 31): Queen's Center for Knowledge-Based Enterprises. 2002.

[46] Sharkie, R. ,Precariousness under the new psychological contract: The effect on trust and the willingness to converse and share knowledge. Knowledge ManagementResearch \& Practice, 2005. $3(1), 37-44$.

[47] Dirks, K. T., \& Ferrin, D. L. ,The role of trust in organizational settings. Organization Science, 2001. 12(4), 450-467.

[48] Ardichvili, A., Page, V., \& Wentling, T. ,Motivation and barriers to participation in virtual knowledge-sharing communities of practice. Journal of Knowledge Management, 2003. 7(1), 64-77.

[49] Hendriks, P. ,Why share knowledge? The influence of ICT on the motivation for knowledge sharing. Knowledge and Process Management, 1999. 6(2), 91-100.

[50] Levin, D. Z., \& Cross, R. ,The strength of weak ties you can trust: The mediating role of trust in effective knowledge transfer. Management Science,2004. 50(11), 1477-1490.

[51] Drucker, P. ,Beyond the information revolution. The Atlantic Monthly,1999. 284, 47.

[52] Maslow, A. H. ,A theory of human motivation. Psychological Review, 1943.50(4), 370-396.

[53] Vincent, M. R. and Quiping, Z. Expertise and Mistakes, To Share or Not to Share. A Cross culture Study of In-group/ out-group Relationship on Knowledge Sharing. Proceedings of the 43rd Hawii International Conference on System Sciences, 2010.

[54] Sophia, S.C. and Joseph, C.S. Knowledge Acquisition Sharing Intention, and Sharing Behavior. International Conference on e-Education, e-Business, e-Management and e-Learning, 2010.

[55] Oye,N.D.;Mazleena,S. and A.Iahad, N.: Challenges of E-learning in Nigerian University Education Based on the Experience of Developed Countries. International Journal of Managing Information Technology,2010, Vol3(2), 39-48.

\section{Authors}

N.D.Oye, receive his M.Tech OR (Operations Research) degree from the Federal University of Technology Yola- Nigeria in 2002. He is a lec-turer in the department of Mathematics and Computer Science in the same Univeristy. At the moment he is a Phd student in the department of Information Systems in the Faculty of computer Science and Infor-mation systems at the Univeristi Teknologi Malaysia, Skudai, Johore, Malaysia. oyenath@yahoo.co.uk

M. Salleh received her Phd in Computer Science at Universiti Teknologi Malaysia in the field of computer networking. Presently she is the Head of Department of Computer Systems and Communication,Faculty of Computer Science and Information Systems, Univerisiti Teknologi Malaysia. Her research areas include computer security, cryptography and networking. mazleena @ fsksm.utm.my

N. A. Iahad has a Phd at the school of informatics, The University of Manchester. Her research areas are: online Learning and asynchronous computer- mediated- communication. Currently she is a senior lecturer in the department of Information systems, in the faculty of Computer Science and Information system, Universiti Teknologi Malaysia. Noorminshah A Ahad <noorminshah@gmail>.. 